\title{
As modalidades mais frequentes de licenciamento realizadas em municípios da região norte do Rio Grande do Sul
}

\author{
The most frequent licensing modalities performed in cities in the northern region of state of Rio Grande do Sul \\ Jordana Georgin', Laudison Lazzari², Alexandre Camponogara ${ }^{3}$,Jean Brun Eloy ${ }^{4}$, Eduardo Pauli ${ }^{5}$
}

Engenharia ambiental, Universidade Federal de Santa Maria

\begin{abstract}
Resumo
O licenciamento é um poderoso mecanismo para incentivar o diálogo setorial, rompendo com a tendência de ações corretivas e individualizadas ao adotar uma postura preventiva, mas pró-ativa, com os diferentes usuários dos recursos naturais. É um momento de aplicação da transversalidade nas políticas setoriais públicas e privadas que interfaceam a questão ambiental. A política de transversalidade para $o$ licenciamento é, por definição, uma política de compartilhamento da responsabilidade para a conservação ambiental por meio do desenvolvimento sustentável do país. Para sua efetividade, os preceitos de proteção ambiental devem ser definitivamente incorporados ao planejamento daqueles setores que fazem uso dos recursos naturais. O objetivo deste trabalho foi analisar as modalidades de licenciamentos emitidas com maior frequência, tanto pela secretaria do meio ambiente das prefeituras dos municípios de Ronda Alta, Rondinha, Sarandi e Três Palmeiras, como pela empresa FTS Florestal e Ambiental, a qual presta serviços de consultoria nesta região.
\end{abstract}

Palavras-chaves: Licenciamento. Conservação ambiental. Recursos naturais.

\begin{abstract}
Licensing is a powerful mechanism to encourage sectoral dialogue, breaking the trend of individualized corrective and support a precautionary approach to actions, but proactive, with different users of natural resources. It is a moment of application of the transverse nature of public and private sector policies that interfaceam environmental issues. The policy of mainstreaming for licensing is, by definition, a policy of sharing the responsibility for environmental conservation through sustainable development. For its effectiveness, the precepts of environmental protection should definitely be incorporated into the planning of the sectors that make use of natural resources. The objective of this study was to examine how licenses issued more frequently, both by the secretariat of the environment of municipalities High Ronda, Rondinha, Sarandi and Three Palms, as the company Forestry and Environmental FTS, which provides consulting services this region.
\end{abstract}

Keywords: Licensing. Environmental conservation. Natural resources. 


\section{INTRODUÇÃO}

O uso dos recursos florestais depende da aprovação prévia do órgão florestal, mediante adoção de técnicas de condução, exploração, recuperação e reposição dos estoques originais.

O Licenciamento Florestal deverá ser requerido pelo proprietário do imóvel em procedimento administrativo próprio, junto ao órgão ambiental competente, através de formulários específicos, dentro das modalidades de licenciamentos florestais estabelecidas pelo órgão ambiental competente, com a documentação necessária conforme o requerimento. O processo licenciatório tem as seguintes etapas: protocolização, análise de documentos, vistoria de laudos técnicos; complementação e/ou alteração de documentos (FEPAM, 2012).

O licenciamento ambiental é o procedimento administrativo pelo qual o órgão ambiental autoriza a localização, instalação, ampliação e operação de empreendimentos e atividades utilizadoras de recursos ambientais, consideradas efetiva ou potencialmente poluidoras, ou daquelas que, sob qualquer forma, possam causar degradação ambiental (MACHADO, 2005).

O licenciamento ambiental é um importante instrumento de gestão da Política Nacional de Meio Ambiente. Por meio dele, a administração pública busca exercer o necessário controle sobre as atividades humanas que interferem nas condições ambientais. Desta forma, tem, por princípio, a conciliação do desenvolvimento econômico com o uso dos recursos naturais, de modo a assegurar a sustentabilidade dos ecossistemas em suas variabilidades físicas, bióticas, sócio-culturais e econômicas. Deve, ainda, estar apoiado por outros instrumentos de planejamento de políticas ambientais, como a avaliação ambiental estratégica; avaliação ambiental integrada; bem como alguns instrumentos de gestão - zoneamento ecológico econômico, planos de manejo de unidades de conservação, planos de bacia, entre outros (FIORILLO, 2003).

A Empresa FTS Florestal e Ambiental Ltda, localizada no município de Ronda Alta - RS, tem a função de prestar serviços de ordem florestal e ambiental em toda a região. Tais serviços como: projetos e licenciamentos ambientais, laudos, levantamentos e avaliações, projetos de reflorestamentos, realização de diagnóstico ambiental, adequação ambiental de atividades agropecuárias, projeto de recuperação de áreas degradadas, laudos de cobertura vegetal, laudos de fauna silvestre, perícia ambiental e florestal, assessoria técnica junto á prefeitura de Ronda Alta e projetos de avaliação de Reserva Legal.

Esta fornece assistência técnica a todos os municípios próximos á região, tais como Ronda Alta, Rondinha, Sarandi e Três Palmeiras, além de prestar serviços de assistência á prefeitura do próprio município onde se localiza.

Nos casos de licenciamentos de pequeno porte, que não requerem a elaboração de projetos, as próprias prefeituras das cidades, na secretaria do ambiente, emitem a autorização para a execução da atividade. Para licenciamentos de maior porte, os quais necessitam de projetos com dados mais detalhados, o requerente deverá procurar uma empresa com profissionais qualificados para a execução de tal tarefa.

O objetivo do trabalho foi realizar um levantamento das modalidades de licenciamentos mais emitidas não só pelas prefeituras locais dos municípios de Ronda Alta, Rondinha, Sarandi e Três Palmeiras, como também pela empresa FTS Florestal e Ambiental Ltda, a qual presta consultoria a estes municípios.

\section{MATERIAIS E MÉTODOS}

Para chegar às modalidades de licenciamento mais emitidas pelas prefeituras dos municípios em estudo, foram visitadas as secretárias de meio ambiente das localidades, bem como a empresa FTS Florestal e Ambiental Ltda, que presta serviços ambientais para estas localidades. Nas prefeituras, foram analisados os documentos arquivados nos últimos cinco anos e selecionados os licenciamentos emitidos com maior frequência. Já na empresa de consultoria ambiental, foram analisados os projetos elaborados no último ano, pois é o período em que esta vem prestando serviços na região. 


\section{RESULTADOS E DISCUSSÕES}

As modalidades de Licenciamento Florestal com maior demanda, realizadas nos municípios de Ronda Alta, Rondinha, Sarandi e Três Palmeiras, foram as seguintes:

Corte raso de árvores nativas plantadas fora da Área de Preservação Permanente (APP), sendo que esta exploração dá prioridade às árvores caídas, isoladas ou danificadas por fenômenos naturais, sendo proibido o corte de espécies da flora ameaçadas de extinção e/ou imunes ao corte, conforme Figura 1.

Manejo de árvores nativas localizadas em área de risco ao patrimônio ou causando riscos de acidentes, fora da área de Preservação Permanente (APP), como se pode observar na Figura 2.

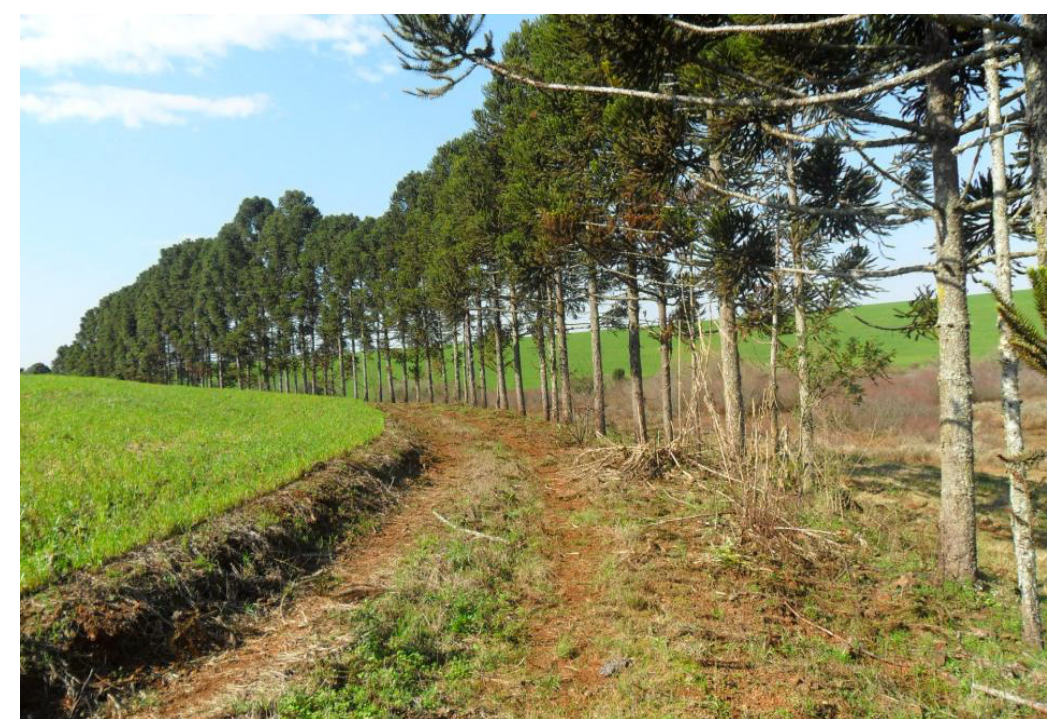

Figura 1 - Árvores para uso na propriedade.

Fonte: Autora.

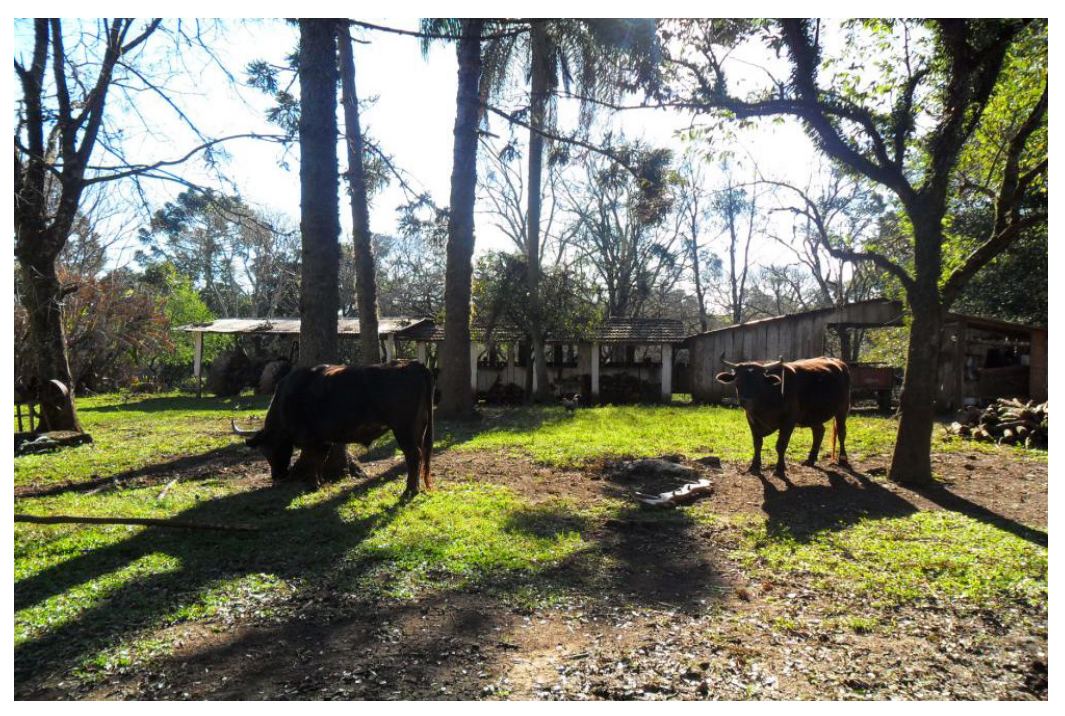

Figura 2- Árvores nativas causando risco ao patrimônio.

Fonte: Autora. 



Figura 3 - (A e B) Araucária danificada por fenômenos naturais.

Fonte: Autora.

Corte de árvore nativa comprovadamente plantada, caída e danificada por fenômenos naturais próximos à propriedade, sendo que o próprio indivíduo fará uso damatéria prima que será originada. Pode-se observar, na Figura 3 (A e B), Araucária danificada por fenômenos naturais.

Supressão de Vegetação em Estágio Inicial de Regeneração Natural, em áreas de até dois hectares, dando ênfase para pequenos produtores rurais, conforme Figura 4.

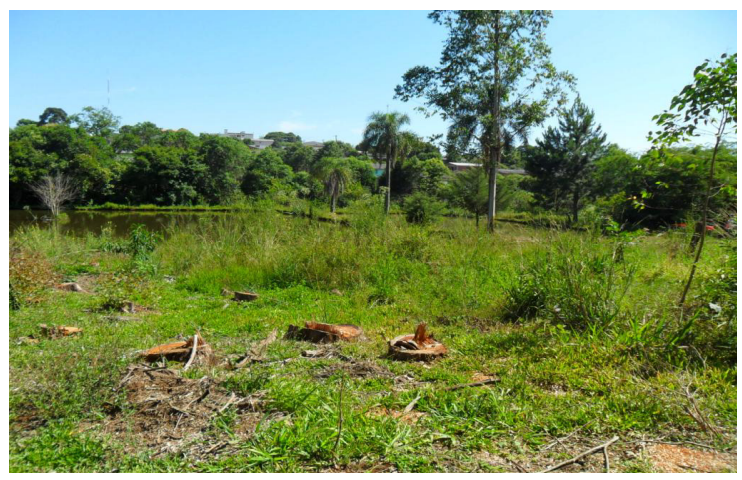

Figura 4 - Vegetação nativa em estágio inicial de regeneração.

Fonte: Autora

Autorização para supressão de exótica em Área de Preservação Permanente (APP), como se pode observar na Figura 5.

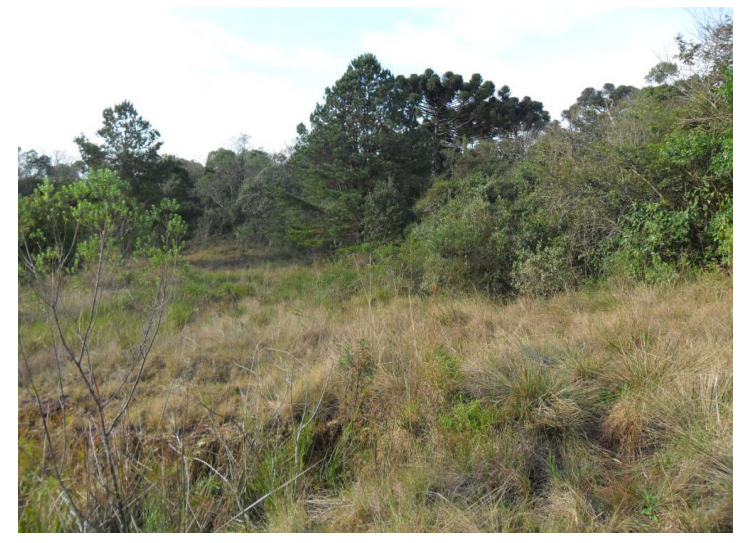

Figura 5 - Exóticas em Área de Preservação Permanente.

Fonte: Autora. 
Todos os Laudos Técnicos eram elaborados a partir das vistorias a campo, posteriormente anexados ao processo de licenciamento, com dados do proprietário do imóvel e dados da propriedade (como localização, registro/matricula do imóvel, bem como as coordenadas geográficas da área a ser manejada), para posterior emissão do Alvará de Licenciamento Florestal ou da Autorização Florestal feito, por um responsável técnico.

O Projeto de Recuperação de Áreas Degradadas surge a partir de um dano causado ao meio ambiente, visando á recuperação de uma área que foi criminalmente degradada. As vistorias de Projetos de Recuperação de Áreas Degradadas (PRAD) eram efetuadas a partir do pedido oficial do Ministério Público ou da Promotoria da Justiça, com posterior emissão do Laudo de Vistoria Técnica, dentro do prazo estabelecido pelo promotor.

Nas vistorias realizadas, observam-se, na Figura 6 (A), as características do local a ser recuperado, bem como a existência de tocos de árvores nativas, comprovando a atividade ilegal que foi realizada no local. Já na Figura 6 (B), nota-se o início da realização do projeto de recuperação realizado pelo responsável técnico.


Figura 6 - (A e B) Vistoria no local do Projeto de Recuperação de Área Degradada (PRAD), bem como o início do projeto de recuperação realizado pelo responsável técnico.

Fonte: Autora.

Durante a sua realização, foram seguidos alguns critérios, estabelecidos pelo profissional responsável técnico, que devem ser cumpridos pelo causador do dano. Entre os critérios, os mais frequentes são: quantidade de mudas e espécies previstas no projeto; tamanho das mudas; estágio sucessional das mudas; preferência para as espécies de ocorrência na região; regeneração natural; isolamento da área, se necessário, evitando, por exemplo, a entrada de animais que podem vir a danificar a área de recuperação; adaptação, das espécies, às condições edafoclimáticas locais; descrição de fauna local; características físicas do local, tais como topografia e hidrografia; controle de formigas e da matocompetição, principalmente, nos primeiros anos de crescimento das mudas; coroamento e tutoramento das mudas.

E, posteriormente, elaborava-se o laudo de vistoria técnica da área vistoriada, com relação ao cumprimento dos objetivos do projeto. Dentre os cumprimentos de maior ocorrência, encontra-se a reposição de mudas de espécies nativas da região, presente na Figura 7 (A e B), com posteriores cuidados como: combate a formigas, coroamento, capina, controle da mato-competição, entre outros cuidados que visam o bom desenvolvimento da muda.

Estes laudos de vistoria técnica podem ser exigidos até o terceiro ano, variando conforme o local se encontra, caso já estiver com uma recuperação estabelecida, isto é, as mudas já estão desenvolvidas 




Figura 7 - (A e B) Reposição de espécies nativas.

Fonte: Autora

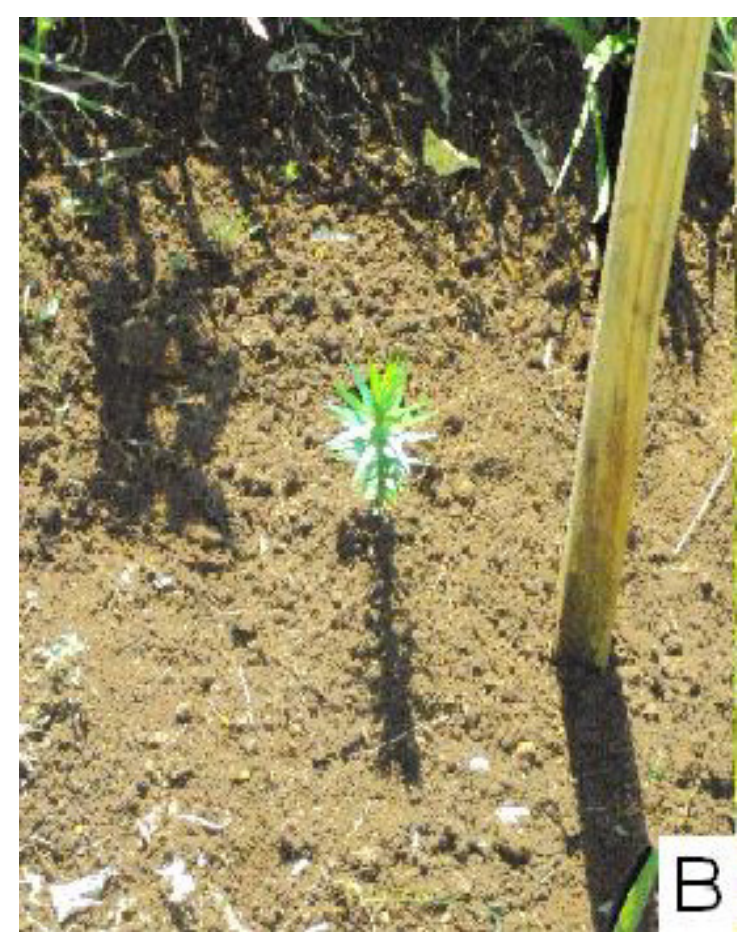

com o comprimento das exigências feitas pelo profissional. É importante salientar que, não havendo mais o risco de morte das plantas no local, a promotora, então, declara o processo por encerrado, não havendo mais a necessidade da elaboração de um novo laudo técnico.

Inventário Florestal, realizado em Área de Preservação Permanente, para a retirada de cerca de 1000 toras de Eucalyptussppara, consumo em serrarias localizadas próximas à região, com posterior manejo de regeneração natural da vegetação nativa local, a fim de recuperar a área, conforme Figura 8 (A e B).


Figura 8 - (A e B) Foto mostrando os exemplares de Eucalipto a serem retirados da APP, bem como a presença de nativas, visando á recuperação da área.

Fonte: Autora. 
Elaboração do Plano de Arborização Urbana no Município de Ronda Alta - RS, por meio das seguintes atividades: Conscientização, por parte da população, das consequências trazidas ao plantar árvores em locais impróprios para o seu desenvolvimento; Realização de um levantamento florístico no município; A principal meta do plano de arborização é trazer conforto ambiental e bem estar às comunidades locais, fatores estes que dependem muito da maneira correta de plantio e das espécies utilizadas. No planejamento da arborização do município de Ronda Alta, foram considerados os aspectos culturais e históricos da população local. Para isso foram, então, realizados sensos nas comunidades locais, levando em conta a opinião da população local e a realização de palestras e cursos gratuitos, motivando e ensinando a população quanto ao manejo e plantio correto de mudas nativas em áreas urbanas, bem como evitando problemas futuros conforme visto na Figura 9 (A e B).
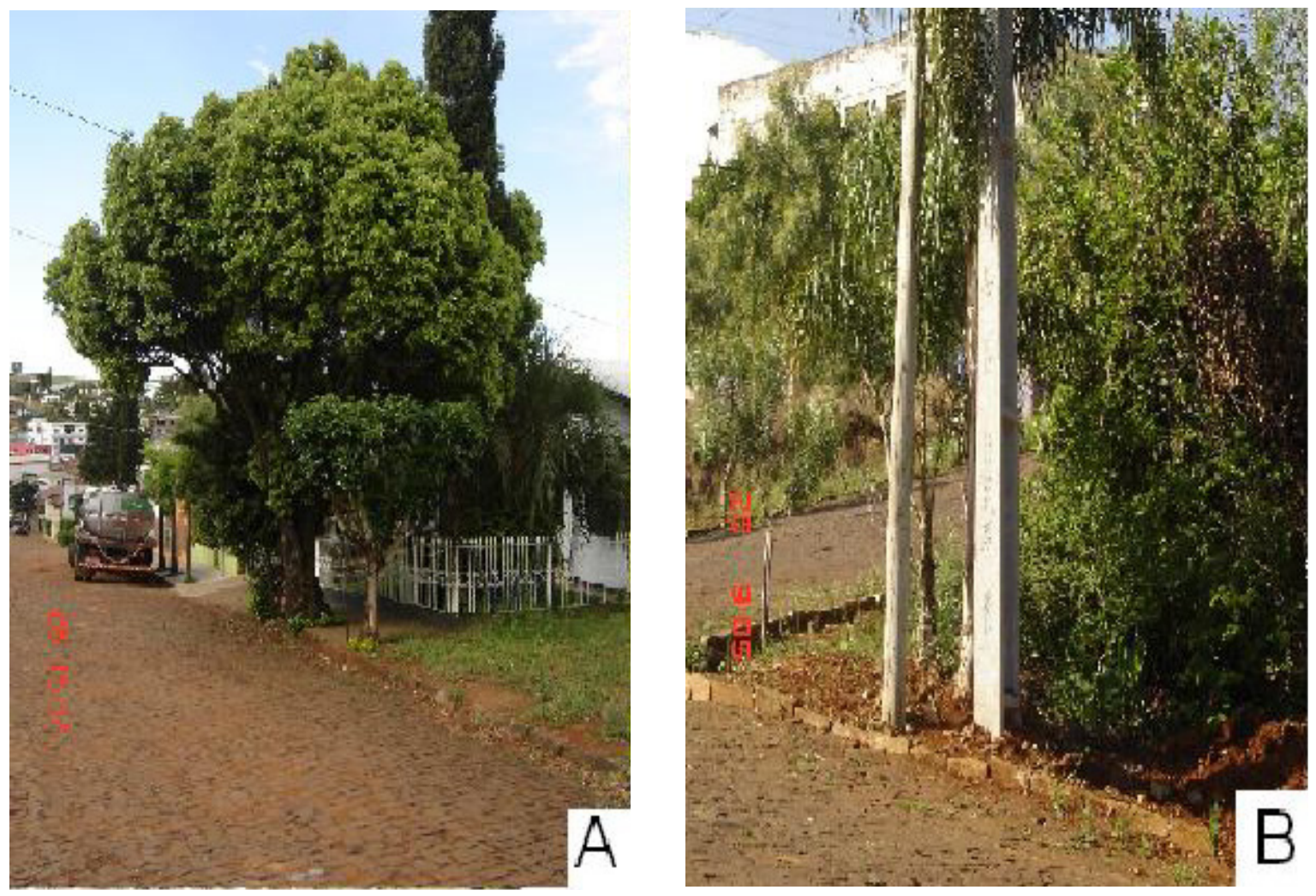

Figura 9 - (A e B) Interferências, causadas na fiação elétrica, por espécies plantadas em locais inadequados.

Fonte: Autora.

Também foi realizada a Averbação da Área de Reserva Legal. A área que está sendo proposta à averbação da reserva legal é constituída por cobertura florestal nativa e se encontra associada a uma área de preservação permanente, devendo o requerente destinar os $20 \%$ de reserva legal em área correspondente a $222.944,2 \mathrm{~m}^{2}$, ou seja, 22,29442 hectares. A propriedade está localizada na Bacia hidrográfica do Rio Passo Fundo/Várzea, mais especificamente ao norte do Planalto Médio, na região fisiográfica da Floresta Ombrófila Mista, em transição com a Floresta Estacional Decidual, com espécies como o Pinheiro-Brasileiro, típicas do planalto médio.

Propõem-se, para a averbação da reserva legal desta propriedade, um fragmento remanescente de floresta ombrófila mista, cuja mata possui extensão de 26,8983 hectares, devendo, o proprietário, recuperar 0,264 hectares com plantio de espécies florestais nativas. A área florestal proposta à Reserva Legal deverá ser e permanecer demarcada e cercada, em nível de campo, e mantida sem intervenções com pastoreio animal no interior da mata, bem como qualquer outra forma de intervenção e manejo no local. Para a área de $2640 \mathrm{~m}^{2}$ de reserva legal a ser restaurada e enriquecida com essências nativas, recomendou-se o plantio simultâneo com a implantação integral do respectivo Projeto de Reparação por dano ambiental. Neste caso, necessita-se da elaboração de um projeto amplo, o qual foi realizado pela empresa FTS Florestal e Ambiental. 


\section{CONCLUSÃO}

Com o presente estudo, podemos concluir que as modalidades de licenciamento ocorrem mais em áreas rurais, com demandas de retirada de alguns indivíduos arbóreos para usos na própria propriedade. As modalidades que exigem elaboração de projetos mais detalhados são pouco frequentes, porém, as que são realizadas pela empresa FTS Florestal e Ambiental são para averbação de reserva legal em propriedades maiores. Os PRAD, Projetos de Recuperação de Áreas Deagradadas, ocorrem com grande frequência, devido aos produtores sofrerem multa por retirada de vegetação natural para o avanço da agricultura. Sendo assim, os produtores devem apresentar, no fórum local, o PRAD, assinado pelo responsável técnico, mostrando a recuperação, com replantio da vegetação natural, da área que foi degradada.

\section{REFERÊNCIAS}

CETESB: Companhia ambiental do estado de São Paulo. Disponível em: $<$ http://www.cetesb.sp.gov.br/licenciamento/licenciamento-ambiental> Acesso em: 12 jun. 2014.

FEPAM: Fundação Estadual de Proteção Ambiental. Disponível em: < http://www.fepam.rs.gov.br $>$ Acesso em: 08 jun. 2014.

FIORILLO, Celso Antônio Pacheco. Curso de direito ambiental brasileiro. 4. ed. São Paulo: Saraiva, 2003.

IBAMA: Instituto brasileiro do meio ambiente e dos recursos naturais renováveis. Disponível em: $<$ http://www. ibama.gov.br/licenciamento> Acesso em: 10 jun. 2014.

IBRAM: Instituto Brasília Ambiental. Disponível em: < $\underline{\text { http://www.ibram.df.gov.br/servicos/licenciamento }}$ -ambiental> Acesso em: 12 jun. 2014.

MACHADO, Paulo Affonso Leme. Direito ambiental brasileiro. 13. ed. São Paulo: Malheiros, 2005.

Ministério do meio ambiente. Disponível em: < http://www.mma.gov.br/> Acesso em: 07 jun. 2014.

SEMA: Secretária do Meio Ambiente. Disponível em: < http://www.sema.rs.gov.br/> Acesso em: 11 jun. 2014.

SMAM: Secretária municipal do Meio Ambiente. Disponível em: $<$ http://www2.portoalegre.rs.gov.br/smam $>$ Acesso em: 8 jun. 2014. 